\title{
Investigating undergraduate students' ideas about the curvature of the Universe
}

\author{
Kim Coble \\ San Francisco State University, San Francisco, California 94132, USA \\ Mallory Conlon \\ University of Illinois at Urbana-Champaign, Urbana, Illinois 61801, USA \\ Janelle M. Bailey \\ Temple University, Philadelphia, Pennsylvania 19122, USA
}

(Received 15 May 2017; published 15 June 2018)

\begin{abstract}
[This paper is part of the Focused Collection on Astronomy Education Research.] As part of a larger project studying undergraduate students' understanding of cosmology, we explored students' ideas about the curvature of the Universe. We investigated preinstruction ideas held by introductory astronomy (ASTRO 101) students at three participating universities and postinstruction ideas at one. Through thematic analysis of responses to questions on three survey forms and preinstruction interviews, we found that prior to instruction a significant fraction of students said the Universe is round. Students' reasoning for this included that the Universe contains round objects, therefore it must also be round, or an incorrect idea that the big bang theory describes an explosion from a central point. We also found that a majority of students think that astronomers use the term curvature to describe properties, such as dimensions, angles, or size, of the Universe or objects in the Universe, or that astronomers use the term curvature to describe the bending of space due to gravity. Students are skeptical that the curvature of the Universe can be measured, to a greater or lesser degree depending on question framing. Postinstruction responses to a multiple-choice exam question and interviews at one university indicate that students are more likely to correctly respond that the Universe as a whole is not curved postinstruction, though the idea that the Universe is round still persists for some students. While we see no evidence that priming with an elliptical or rectangular map of the cosmic microwave background on a postinstruction exam affects responses, students do cite visualizations such as diagrams among the reasons for their responses in preinstruction surveys.
\end{abstract}

DOI: 10.1103/PhysRevPhysEducRes.14.010144

\section{INTRODUCTION}

\section{A. Motivation and framework}

As astronomers continue to develop a deeper understanding of the Universe's structure, composition, and evolution, it is important to identify the possible alternate conceptions students have about these topics so that astronomy instructors can effectively incorporate this new information into their curricula. Addressing students' alternative conceptions and increasing scientific literacy are critical to addressing calls for education reform at all levels [1-7], including at the college level [8].

\footnotetext{
Corresponding author. kcoble@sfsu.edu

Published by the American Physical Society under the terms of the Creative Commons Attribution 4.0 International license. Further distribution of this work must maintain attribution to the author(s) and the published article's title, journal citation, and DOI.
}

While there is a wealth of studies exploring students' alternative conceptions about geocentric astronomy topics (e.g., seasons, moon phases), historically fewer studies have explored students' conceptions about cosmology (see, e.g., Refs. $[9,10]$ and references therein). Those that do exist tend to favor the few specific topics relevant at the $\mathrm{K}-12$ level (even when studied at the college level), such as the definition and evidence for the big bang theory [11-13], without going into more advanced topics. Simulations and visualizations, some relating to cosmology and large distance scales, have also provided an area of investigation $[14,15]$. Providing introductory astronomy courses that are based on a current view of the Universe and a modern treatment of science contributes to the development of a more scientifically literate society [16]. While measuring the overall curvature of the Universe to high precision via observations of the cosmic microwave background $[17,18]$ has been one of the major triumphs of modern cosmological science, to our knowledge there have been no studies specifically investigating students' ideas about the 
curvature of the Universe to date. The present study provides a first step by cataloging students' understanding of this topic both prior to and after instruction.

The longstanding field of conceptual change research provides a frame for our research $[19,20]$. This approach assumes that students may have ways of thinking that differ from expert thinking, and that these ideas can either help or hinder the process of learning in new situations [21]. Conceptual change research attempts to understand the mechanisms behind the assimilation or accommodation, such as described by Piaget, of new knowledge [19]. One early component of conceptual change research has included the identificationbeyond the anecdotal sense of the instructor - of the ideas students bring with them into an instructional setting [22]. Knowledge of these initial ideas can inform instruction, particularly through scaffolding for content that might be more challenging to understand. In the present study, we attempt to systematically identify students' ideas around the curvature of the Universe present before and after instruction in an introductory astronomy course.

Criticisms of conceptual change research [23] are not without basis, but the idea of using students' prior knowledge in order to inform instruction continues to be a mainstay of education. For example, conceptual change work such as that done by Posner et al. [20] has been criticized for assuming students' learning to be a rational and logical process [24,25]. The present study does not look at the change process itself but rather simply explores the ideas students have both before and after instruction. As such, this study serves as an exploratory foundation on which future research might build, in a similar manner to the other studies in our larger research program [26-29] and similar studies in astronomy education research that explore students' preinstructional understanding [12,30-32]. It is not the case, however, that we specifically use a conceptual change approach to instruction [33] nor claim to robustly measure conceptual change, such as through the use of large-scale measures like concept inventories or an in-depth qualitative study, in the present study.

\section{B. Astronomy background}

In this section, we summarize some of the major principles and measurements that have led cosmologists to our current understanding of the curvature of the Universe. From general relativity, we know that matter and energy bend spacetime [34]. This is true near objects in space, such as planets, stars, galaxies, and clusters of galaxies, and can be detected through gravitational lensing. This is also true for the Universe as a whole. The Friedmann equation relates the matter and energy contents of the Universe to its expansion and curvature. In principle, the Universe might have a familiar Euclidean geometry, in which parallel lines stay parallel and the angles of triangles add up to 180 degrees. Such a space has zero curvature and is said to be "flat." This does not mean two dimensional, like a pancake; space is still three dimensional, but it is not curved in any of those dimensions. Alternatively, the Universe might have a different geometry, for example, a spherical geometry, with positive curvature, analogous to the surface of Earth, or a hyperbolic geometry, with negative curvature, similar to a saddle or a potato chip.

Depending on the curvature of space, objects of a given physical size will look smaller or larger due to light rays following geodesics in that space. Specifically, objects in a space with positive curvature will look larger than objects in a space with zero curvature, which will in turn look larger than objects in a space with negative curvature. One such standard astronomical "ruler" we can measure is related to the horizon size of the Universe at the time the cosmic microwave background (CMB) formed [35-37]. The CMB is relic radiation from a time when electrons became bound to atoms and the Universe transitioned from a hot, dense, opaque state to one that was transparent, where photons could travel freely through the Universe. Current research suggests this happened when the Universe was 380000 years old [18]. Prior to that time, photons were tightly coupled to ionized matter by Thomson scattering in a photon-baryon fluid. Small quantum fluctuations in the density of the early Universe, enhanced by acoustic oscillations in the photon-baryon fluid, were the seeds of structure formation, seen as anisotropy (temperature differences) of approximately 10-100 parts per million in the $\mathrm{CMB}$, and later in the large-scale distribution of galaxies.

In much the same way that the fundamental mode of sound waves in a musical instrument is related to the instrument's size, the fundamental mode of acoustic oscillations in the photon-baryon fluid of the early Universe is related to the horizon size of the Universe at the time the CMB formed. The characteristic angular scale of the hot and cold spots in a map of the CMB anisotropy pattern will be different primarily due to the curvature of space as a whole, because of the geometrical projection effect described above. The characteristic angular scale will be larger if the Universe is positively curved than if it is not curved and smaller if it is negatively curved; for a Euclidean geometry (i.e., zero curvature), this scale will be $\sim 1$ degree on the sky. Figure 1 shows a map of $\mathrm{CMB}$ anisotropy as measured by BOOMERANG [17] along with the CMB anisotropy pattern for three theoretical models of different curvature. To compare data and models more precisely, the map is decomposed into a power spectrum of angular scales. The curvature of the Universe is currently measured to be zero to subpercent precision $(0.000 \pm 0.005)$, by comparing CMB measurements and measurement of the acoustic horizon scale from the clustering of galaxies $[18,38]$ with models of structure formation that depend on a number of cosmological parameters, including curvature based on Refs. [39,40,41].

\section{Present study}

This study is one in a series of studies that examines the nature and frequency of undergraduate students' ideas 

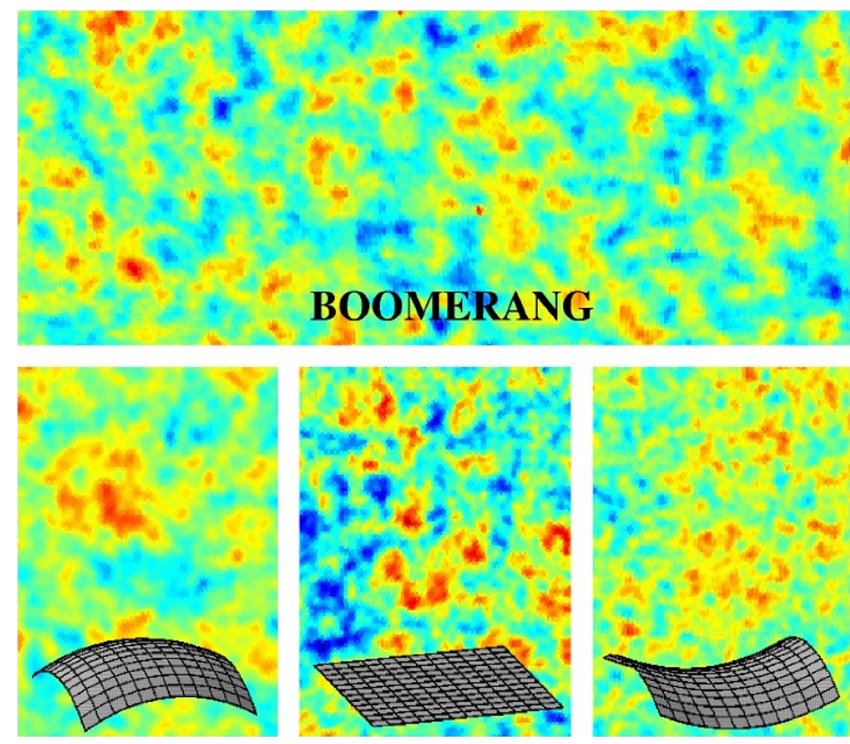

FIG. 1. Maps of the CMB will have a different characteristic angular scale depending on the curvature of space. In a spherical space (positive curvature, bottom left), the typical size of the hot and cold spots in the CMB will be larger than in a "flat" space (zero curvature, bottom middle) and will be smaller in a hyperbolic space (negative curvature, bottom right). By comparing models to data (top panel), the BOOMERANG team determined that the Universe as a whole is not curved. From the BOOMERANG Team. ${ }^{1}$

about cosmology: the structure, composition, and evolution of the Universe. Our goal in this study is to document and interpret students' ideas about the curvature of the Universe. Our methods, described fully in the next section, are similar to those used in other components of our larger project, including Coble et al. [26], where they explored students' ideas on distance and structure; Coble et al. [27] where they explored students' ideas on the composition of the Universe; and Conlon et al. [28] where they explored students' ideas on the fate of the Universe. Trouille et al. [29] investigated students' ideas on the big bang theory and the age, expansion, and history of the Universe. Bailey et al. [30] presented the results of a nationwide, open-response, preinstruction survey on various cosmological topics, including those discussed in Coble et al. [26,27] and Trouille et al. [29].

The research questions addressed in this study are as follows:

(1) What are students' preinstruction ideas on the curvature of the Universe?

(2) What are students' postinstruction ideas on the curvature of the Universe?

(3) Does priming with different astronomical visualizations of the CMB affect students' responses on questions relating to curvature?

In Sec. II, we describe our methods, including the setting, participants, data sources, analysis procedure,

\footnotetext{
${ }^{1}$ http://oberon.roma1.infn.it/boomerang/pressrelease/.
}

and validity. We then present students' ideas about the curvature of the Universe in Sec. III. In Secs. IV and V, we conclude with a discussion and the implications of our most important results.

\section{METHODS}

\section{A. Methodological framework}

In this study, we used a mixed-methods approach, specifically a convergent design [42], in collecting and analyzing the data. A convergent design has both qualitative and quantitative data collected concurrently (in our case, within the same semester), and is thus "an efficient design" [42] (p. 78). Data are analyzed separately, then subsequently compared. The use of multiple data streams can be a powerful approach to answering research questions $[43,44]$.

\section{B. Participants and setting}

ASTRO 101 is a colloquial term for any introductory undergraduate course designed to give a broad overview of astronomy, including cosmology $[45,46]$. The ASTRO 101 courses examined in this study, comprised of a convenience sample, were taught at three American undergraduate institutions: Chicago State University (CSU), an urban minorityserving university located in the Midwest; Concord University (CU), a regional state university in Appalachia; and the University of Nevada-Las Vegas (UNLV), an urban research-intensive university located in the western United States. Preinstructional data collection took place at all three institutions, while postinstruction data were collected only at CSU, where one of the authors was an instructor of participating courses. Although individual demographic data were not collected in order to maintain anonymity and to reduce the time required for the research task, students' demographics for the ASTRO 101 courses are generally representative of each university's undergraduate population as a whole because the courses satisfy general education requirements for all students. See Table I for details on each university's undergraduate demographics. Table I also includes previous astronomy experience, as self-reported by students on the survey forms.

\section{Data collection}

The data set for this study includes responses to questions on three preinstruction survey forms at three universities (CSU, CU, and UNLV), a postinstruction exam question from one university (CSU), and interviews conducted at one university (CSU). Details on the preinstruction survey questions, postinstruction exam question, and interviews can be found in Tables II-IV. The numbers reported are totaled over all applicable semesters unless otherwise indicated. The number of responses vary across class sections for a variety of reasons, including not all students responded to the exam or survey question, and some courses have lower enrollment than others. 
TABLE I. Students' demographics for each university. ${ }^{2}$

\begin{tabular}{|c|c|c|c|c|c|c|}
\hline \multirow{3}{*}{$\begin{array}{l}\text { University } \\
\text { Chicago State } \\
\text { University (CSU) }\end{array}$} & \multirow{2}{*}{\multicolumn{3}{|c|}{ University Demographics }} & \multicolumn{3}{|c|}{ Taken astronomy before? } \\
\hline & & & & \multirow{2}{*}{$\begin{array}{l}\text { Yes } \\
3 \%\end{array}$} & \multirow{2}{*}{$\begin{array}{c}\text { No } \\
70 \%\end{array}$} & \multirow{2}{*}{$\begin{array}{c}\text { No response } \\
27 \%\end{array}$} \\
\hline & $\begin{array}{l}\text { 78\% African } \\
\text { American } \\
\text { 1\% Asian/Pacific } \\
\text { Islander } \\
6 \% \text { Hispanic } \\
\text { 2\% White }\end{array}$ & $\begin{array}{l}71 \% \\
\text { Female }\end{array}$ & $\begin{array}{l}\text { Average } \\
\text { age: } 29\end{array}$ & & & \\
\hline $\begin{array}{l}\text { Concord } \\
\text { University (CU) }\end{array}$ & $\begin{array}{l}\text { 6\% African } \\
\text { American } \\
\text { 1\% Asian/Pacific } \\
\text { Islander } \\
\text { 1\% Hispanic } \\
\text { 87\% White }\end{array}$ & $\begin{array}{l}57 \% \\
\text { Female }\end{array}$ & $\begin{array}{l}\text { Average } \\
\text { age: } 23\end{array}$ & $5 \%$ & $68 \%$ & $27 \%$ \\
\hline $\begin{array}{l}\text { University of } \\
\text { Nevada-Las } \\
\text { Vegas } \\
\text { (UNLV) }\end{array}$ & $\begin{array}{l}\text { 8\% African } \\
\text { American } \\
\text { 18\% Asian/Pacific } \\
\text { Islander } \\
\text { 23\% Hispanic } \\
38 \% \text { White }\end{array}$ & $\begin{array}{l}56 \% \\
\text { Female }\end{array}$ & $\begin{array}{l}\text { Average } \\
\text { age: } 22\end{array}$ & $9 \%$ & $62 \%$ & $29 \%$ \\
\hline
\end{tabular}

TABLE II. Preinstruction survey questions.

\begin{tabular}{llc}
\hline \hline Form & \multicolumn{1}{c}{ Question } & N, University (semester) \\
\hline Q1 (Form B') & $\begin{array}{l}\text { What is the shape or geometry of the Universe? } \\
\text { How do we know? }\end{array}$ & $\begin{array}{c}(N=16) \\
\text { CU (Spring 2011) }\end{array}$ \\
Q2 (Form E) & $\begin{array}{l}\text { Which of the following best describes the "geometry" or } \\
\text { "curvature" of space (the Universe)? (a) Round (b) Flat } \\
\text { (c) Hyperbolic (d) Some other (e) No way to know. }\end{array}$ & $\begin{array}{c}\text { CSU (Fall 2012, Spring 2013, Spring 2014) } \\
\text { Why did you select the answer you chose? }\end{array}$ \\
& $\begin{array}{l}\text { What do astronomers mean when they talk about the } \\
\text { "shape" or "curvature" of space (the Universe)? } \\
\text { Q3 (Form D) }\end{array}$ & UNL (5 sections, Fall 2011-Spring 2012) \\
& How do they measure this trait? & CU (Spring 2013) \\
& & CSU (Fall 2012, Spring 2013) \\
\hline \hline
\end{tabular}

TABLE III. Postinstruction exam question $(N=75)$.

Question: What does the cosmic microwave background tell us about the overall curvature of the Universe?
Answer choices:
a. It has a spherical (positive) curvature
b. It has a saddle-shaped (negative) curvature
c. It has no (zero) curvature
d. It could be any of these; the data is not yet good enough to tell

\footnotetext{
${ }^{2}$ Demographic citations: http://www.csu.edu/IER/documents/ factBook2013-1'4.pdf http://hub.concord.edu/ir/sites/hub.concord .edu.ir/files/CU\%202013-2014\%20Common\%20Data\%20Set.pdf https://ir.unlv.edu/IAP/Reports/Content/UndergraduateStudentProfile_ Fall2013.aspx.
}

Preinstruction surveys were given during the first week of instruction to students in 13 ASTRO 101 course sections over seven semesters (Fall 2010, Spring 2011, Fall 2011, Spring 2012, Fall 2012, Spring 2013, and Spring 2014). Three different forms (labeled D, E, and $\mathrm{F}$ in continuing from prior work [30]) were randomly dispersed among the students in 
TABLE IV. Interviews in which students discussed the shape or curvature of the Universe $(N=9)$. In the first three interviews students spontaneously discussed the topic, whereas in the last six students were asked directly to address it.

\begin{tabular}{|c|c|c|c|}
\hline Student & Semester & Pre or post & Initial question asked \\
\hline 1 & Spring 2009 & Pre & What objects do you think are in the Universe and how do you think they are arranged? \\
\hline 2 & Spring 2009 & Pre & What objects do you think are in the Universe and how do you think they are arranged? \\
\hline 3 & Spring 2009 & Post $^{\mathrm{b}}$ & $\begin{array}{l}\text { Is there anything that you believed or learned or heard before you took this class that } \\
\text { conflicts with what you've learned in this class? }\end{array}$ \\
\hline 4 & Fall 2010 & Post $^{b}$ & What do you think the shape or the geometry of the Universe is? \\
\hline 5 & Fall 2010 & Post & $\begin{array}{l}\text { Have you ever thought about the shape of the Universe? Or the shape of space? What did } \\
\text { you think about it before the class or after the class? }\end{array}$ \\
\hline 6 & Fall 2010 & Post & What about the shape of the Universe? Did you ever think about that before the course? \\
\hline 7 & Fall 2010 & Post $^{\mathrm{b}}$ & $\begin{array}{l}\text { What about the shape of the Universe? Did you ever think about that before class, how the } \\
\text { space might be curved? How do you think about it now? }\end{array}$ \\
\hline 8 & Fall 2012 & Pre & $\begin{array}{l}\text { What about the shape or curvature of space with regard to the Universe, like the overall } \\
\text { shape or curvature of the Universe? }\end{array}$ \\
\hline 9 & Fall 2012 & Post $^{b}$ & $\begin{array}{l}\text { What do you think astronomers mean when they talk about the shape of the Universe or } \\
\text { the curvature of space, and how do they measure this trait? }\end{array}$ \\
\hline
\end{tabular}

${ }^{\text {a}}$ These questions did not directly ask about curvature of the Universe but these students' responses included a discussion of curvature in response to them.

${ }^{\mathrm{b}}$ Students who were interviewed postinstruction who also discussed their preinstruction ideas.

each section. This was done to get a sample of responses to several different questions while keeping the survey-and thus the time requirements for administering it-short. Although approximately even numbers of each form were available for distribution, the final number of surveys received varied due to the distribution patterns and participant completion. For the present study, we looked at responses to three questions that specifically relate to the curvature of the Universe. Form F did not have any questions about curvature and so will not be discussed here.

In developing the questions, we used combinations of the words shape, geometry, and curvature, as well as space and Universe, to probe students' ideas about the curvature of the Universe. One challenge with this topic is that the astronomical meaning is quite different than students' everyday use of these words, and it was not clear at the outset which might best lend itself to eliciting the type of answer desired. First, a preliminary open-ended question (Q1) was administered to a small number of students $(N=16)$ as a test case during Fall 2010-Spring 2011, placed on a modification of one of our earlier forms that we call form $\mathrm{B}^{\prime}$. Informed by the results, the other questions $(\mathrm{Q} 2, \mathrm{Q} 3)$ were placed on forms $\mathrm{E}(N=265)$ and $\mathrm{D}(N=225)$, respectively, for the Fall 2011-Spring 2014 semesters. An early analysis of Q1 showed that students were not responding with flat or hyperbolic, both terms that astronomers would use in considering the curvature of the Universe. Thus, Q2 incorporated these terms explicitly to see whether students recognized them. To determine if students had in mind the same concept of curvature as our team, we asked an openended survey question (Q3) on what students think astronomers mean by the shape or curvature of the Universe.

The postinstruction exam question was given during the last week of regular classes at CSU over seven semesters during the time period of Fall 2008-Spring 2014. It was a multiple-choice question on what the cosmic microwave background tells us about the overall curvature of the Universe. The correct answer choice is shown in bold in Table III. Wondering whether students' responses might be affected by different visualizations, we intentionally put a map of the CMB in one of two different styles on the exam. In some cases, an elliptical projection was used while in others a rectangular one was used (Fig. 2). The maps were not used for the question on curvature, but for a different question on the exam about the CMB.

As part of our larger study, we also conducted semistructured interviews with CSU ASTRO 101 students to corroborate and illustrate the themes we saw in survey and exam responses. Students were asked various questions about cosmological topics, including one question that specifically asked about shape of the Universe. Interviews with nine students over three semesters (Spring 2009, Fall 2010, and Fall 2012) probed students' ideas about the curvature of the Universe (Table IV). In six of the interviews, students were asked about the shape directly, whereas in the other three the topic was discussed spontaneously in response to other questions. Three of the interviews were conducted prior to instruction in cosmology and six were conducted after. Four of the students interviewed postinstruction also spoke of their preinstruction ideas. Thus, we have a total of $N=7$ preinstruction and $N=6$ postinstruction interviews that addressed curvature of the Universe either directly (through researcher questions) or indirectly (through student responses to other questions).

\section{Data analysis}

For the preinstruction surveys and interviews, we carried out a content analysis [47] through an iterative process of open coding to identify themes that emerged from the set of responses. One researcher read the students' responses to 

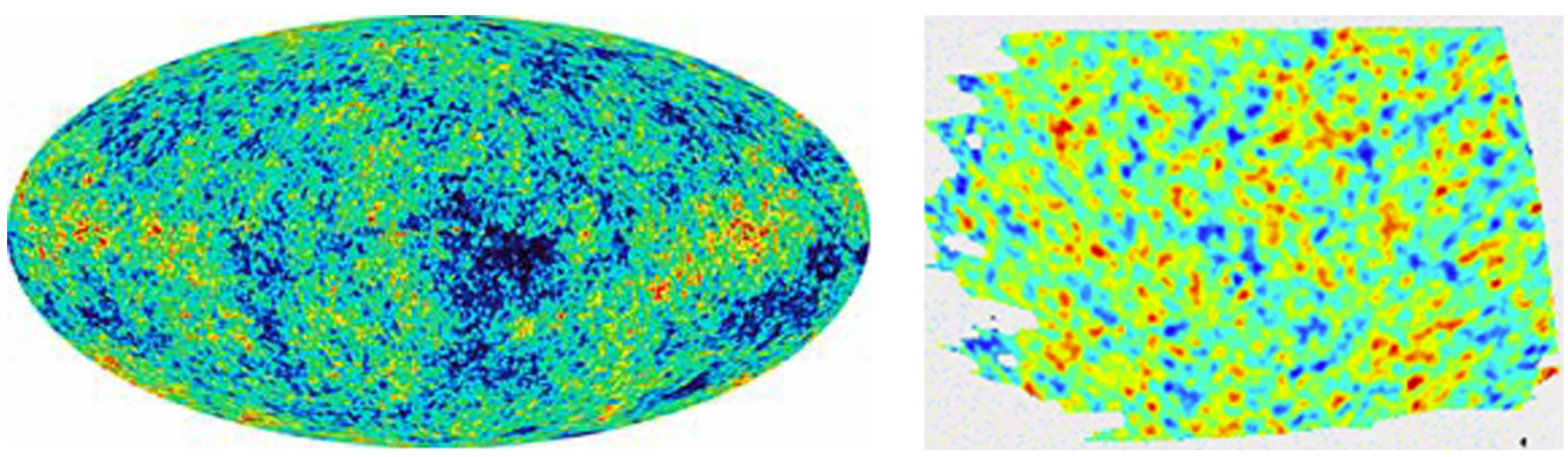

FIG. 2. (Left) An elliptical map of the CMB. Credit: WMAP. ${ }^{3}$ (Right) A rectangular map of the CMB. From BOOMERANG. ${ }^{4}$

each survey question and recorded the common themes observed. This process was repeated until no new themes emerged and the resulting list was considered comprehensive. Each theme was then assigned a short code and codes were grouped where appropriate [47,48]. All responses were coded for themes. The themes were then quantified by looking at frequency of their appearance across the participating schools and as a whole.

We defined an emergent theme as a response type that was coded at least three times throughout the students' preinstruction responses. Codes that appeared fewer than three times throughout the students' preinstruction responses were coded as other. We then identified the fraction of students who discussed a given theme in their response. Thematic codes and examples of each code for the preinstruction surveys can be found in Tables V-VII. Students' responses could be assigned multiple codes as appropriate. Interview responses were also coded thematically for shape, with the addition of a code for "flat."

\section{E. Validity}

The validity of the survey and interview coding and interpretation was established primarily through the use of multiple research team members. Coding by two of us ensured a common understanding of the responses as well as our interpretation of them. Other members of the project served as peer debriefers [48], who reviewed aspects of the coding and analysis at various points in time and contributed to the credibility of the interpretations.

Interrater reliability, as calculated by kappa, ranged from 0.687 to 0.886 (all $p<0.001$ ), depending upon the survey question or interview; these values of kappa are considered "substantial" to "almost perfect" (see Landis and Koch, as cited in Ref. [49]). For those responses on which the codes differed between researchers, the selections were negotiated as needed until we came to $100 \%$ agreement on the

\footnotetext{
${ }^{3}$ https://map.gsfc.nasa.gov.

${ }^{4}$ http://oberon.roma1.infn.it/boomerang/pressrelease/.
}

final codes to be assigned. Codes were recorded for each question and documented in a spreadsheet. The final negotiated codes were used for the results presented below.

We used a Kruskal-Wallis (KW) test to determine whether we could aggregate results from different course sections for each question (e.g., Q1 across sections). The KW test is a nonparametric method for testing the hypothesis that three or more sample populations (in our case, the coded students' responses from each semester) have the same mean distribution, against the hypothesis that they differ [50]. One advantage of the KW test is that it can be applied to data sets in which the number of values from each semester are of equal or unequal lengths. That is, the KW test is valid for comparing responses from different numbers of students across semesters. To use the KW test, each sample population must have five or more responses, which we had in our study. For this study, we used a significance level of 0.05 . If our $p$ value was greater than 0.05 , we did not reject the null hypothesis that the semester results come from the same parent population. In other words, $p>0.05$ meant we could aggregate our sample population, because the sample populations did not appear to differ significantly from one another. For the ASTRO 101 preinstruction surveys and the CSU postinstruction exam question, we ran a KW test to determine whether the different semesters' and universities' data could be combined. The $p$ value was greater than 0.05 in every case, so we are confident in aggregating results across semesters and universities.

\section{RESULTS}

\section{A. Preinstruction surveys: Curvature of the Universe}

Here we present our results on students' preinstruction ideas about the curvature of the Universe as measured by survey questions Q1, Q2, and Q3.

In response to the open-ended question, What is the shape or geometry of the Universe? (Q1a, $N=16$ ), students overwhelmingly responded that the Universe is circular, spherical, round, or has a central point (63\%). An additional quarter of the students either did not respond or 
TABLE V. Thematic coding scheme for preinstruction survey question 1 .

\begin{tabular}{ll}
\hline \hline Thematic code & \multicolumn{1}{c}{ Examples } \\
\hline $\begin{array}{l}\text { (a) Shape } \\
\text { Round or has a central point }\end{array}$ & "Circle because every picture I have seen shows the universe [being] round." \\
No shape & "The universe has no specific shape or pattern." \\
Expanding Universe & "The universe is roughly globelike, constantly expanding" \\
Infinite Universe & "The shape or geometry of the universe is infinite and limitlessly expanding." \\
Open space & "There is no shape, open space" \\
No response, I don't know, nonserious & "No idea" \\
(b) How do we know & "That's the way the planets are arranged." \\
Round objects & "We know this because of past people finding out." \\
Authority & "Using the big bang theory, the explosion sent all sorts of mater in all directions." \\
Big bang theory & "We know by astronomers that have viewed how our universe is." \\
Observations & "We know some but not enough to define this shape or patterns." \\
We don't know & "No idea" \\
No-response, I don't know, nonserious &
\end{tabular}

TABLE VI. Thematic coding scheme for preinstruction survey question $2 \mathrm{~b}$.

\begin{tabular}{ll}
\hline \hline Thematic code & Examples \\
\hline Big bang theory & "You can see stars in every direction, but also during the big bang, \\
it would've been blown up in a spherical shape." & "Curvature and geometry have a lot to do with round objects and the \\
universe is built in a round form." & "I think I read it somewhere" \\
Objects in Universe & "Sounded most logical" \\
"I don't know how it's measured." & "Because we don't know the full scope of the universe yet." \\
Buthority & "I don't think there is a way to figure out the entire universe." \\
I don't know & "Because the universe is [infinite] therefore you cannot describe the geometry \\
Don't know yet & or curvature of it." \\
No way to know & "Because the universe is expanding." \\
Infinite Universe & "The universe has many galaxies. In our galaxy we have 9 planets." \\
Expanding Universe &
\end{tabular}

responded I don't know. A handful of other responses were seen, as shown in Fig. 3. In a multiple-choice question (Q2a, $N=265)$, students were presented with options for the curvature of the Universe as considered by scientists, plus an additional option of no way to know. For this question, no way to know was the most popular response $(37 \%)$, followed by round $(29 \%)$. Full results are shown in Fig. 4.

In the second part of the open-ended questions, students were asked the questions either how we know the geometry (Q1b, $N=16$ ) or why they selected the answer they chose for the geometry (Q2b, $N=265)$. We used heat maps to correlate students' responses for the geometry with their reasoning provided. Figure 5 shows the results for Q1 and Fig. 6 shows the results for Q2. The heat maps can be thought of as analogous to false color astronomical images; areas in the matrices that are colored orange and yellow represent more common response combinations and those that are colored blue or dark gray represent less common response combinations. Figures 5 and 6 both use a color scheme based on a rainbow color palate, but they are not exactly the same. The number of responses coded with a particular combination of curvature and reasoning is given in each cell. Numbers may add up to more than the number of respondents because more than one theme may be coded per response. ${ }^{5}$

By examining Figures 5 and 6, we found several trends in the relationships between students' ideas and their reasoning:

- Students who responded there is no way to know the geometry of the Universe in Q2 most often reported they chose that answer because: the Universe is too big (or infinite) so we cannot know (30\%); there is no way to know or that the curvature cannot be measured (24\%); because we don't know yet (but implicitly suggesting that it would be possible to know in the future; 20\%); or that they themselves didn't know $(18 \%)$.

\footnotetext{
${ }^{5}$ In Figs. 5 and 6, the abbreviations are as follows: Universe (U), I don't know (IDK), No response (NR), Nonserious response (NSR), Irrelevant (IRR).
} 
TABLE VII. Thematic coding scheme for preinstruction survey question 3.

Thematic code Examples

(a) What do astronomers mean?

Properties of the Universe

"When astronomers refer to the 'shape' of the universe, they are referring to the physical shape of the observable universe."

Properties of objects in the Universe

"I assume that shape refer to whether something like a planet is a circle or an oval or how much of an oval it is."

Gravity or fabric of space

"Space and time are connected and are considered a type of 'fabric.' This fabric can theoretically be manipulated by objects in space."

Expanding Universe

Specified shape

"They refer to how the universe is expanding."

"Shape/curvature is generally referring to a spherical shape that the universe took on as it expanded."

Arrangement

What the Universe consists of

"This refers to the alignment of planets in correlation to moons and stars."

"Astronomers are referring to the contents that make up space i.e. stars, galaxies, planets etc."

"Formation"

Infinite Universe

"The way space is formed."

"It is never ending."

"What the universe includes and how boundaries are set."

Boundaries of Universe

Motion

"They are discussing the shape of the path in which the universe and all its objects circulate."

Our interpretation

"They are talking about the relationship between our perception of the universe as beings built with gravity and the universe which doesn't have gravity through its entirety."

Other

"The shape is different [than] what we would probably expect."

"The shape has to be a tree that expand really far."

(b) How do they measure it?

Make observations

In light years

Light bent by massive objects

"They measure this trait by observing what is in the universe."

"I believe this trait is measured in light-years."

"To measure it, if light is traveling near a large body with gravitational pull, it can warp the path that the light is traveling on, changing the amount of distance that light must travel."

With math

"They measure this trait with math."

"Theoretical physics is used to measure the curve of space."

"There is no measure. It's infinite and always expanding."

Can't be measured

Authority

"I've seen many diagrams of it by watching NOVA and the Science Channel. Wish I could remember more.... Neil DeGrasse Tyson would be so disappointed in me"

No-response, I don't know, nonserious "They measure it with the 'How far is this really' app on the Apple iPhone."

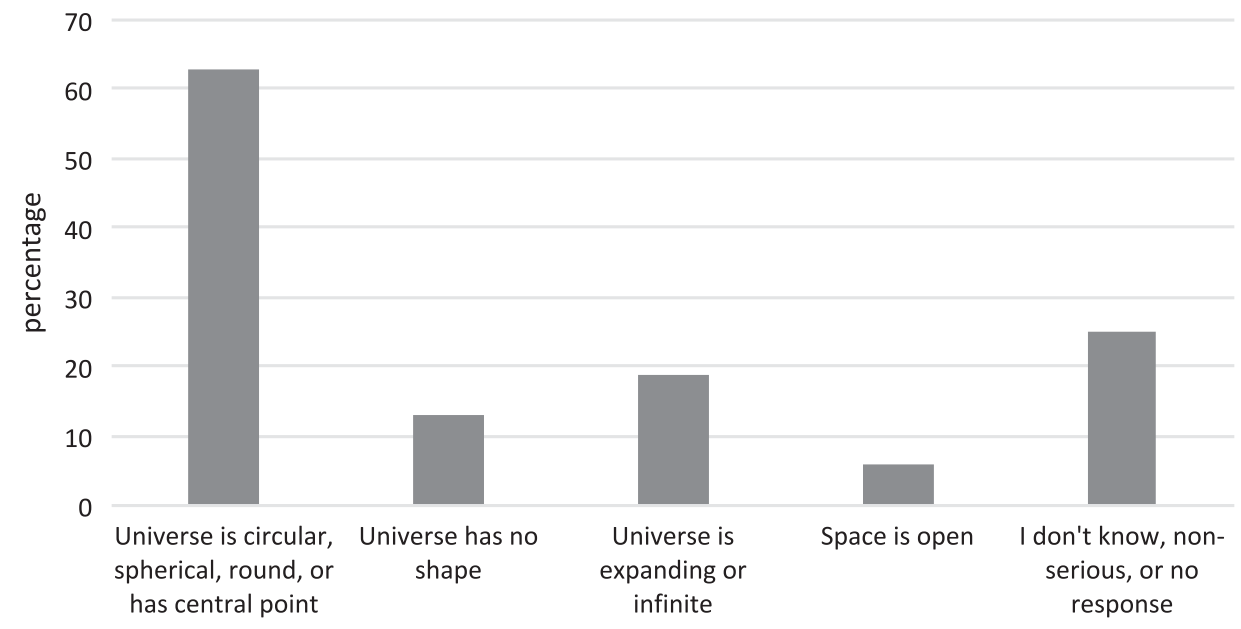

FIG. 3. ASTRO 101 preinstruction survey responses for What is the shape or geometry of the Universe? $(N=16)$. 


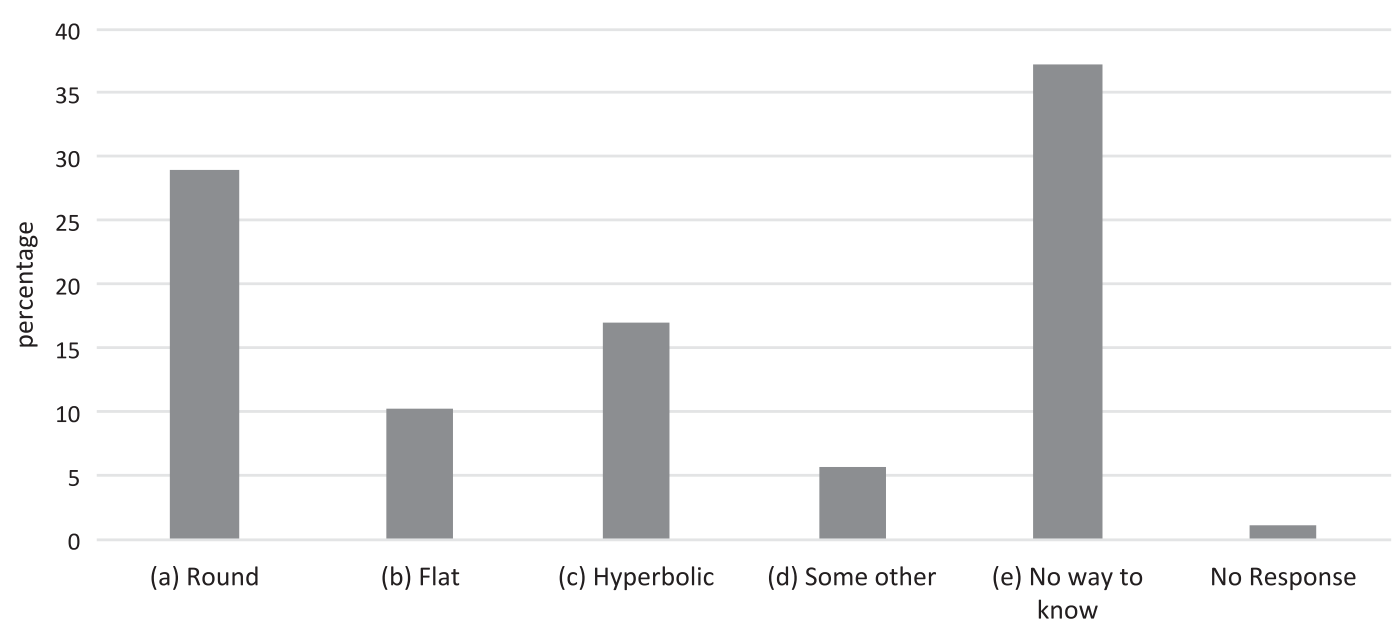

FIG. 4. ASTRO 101 preinstruction survey responses for Which of the following best describes the "geometry" or "curvature" of space (the Universe)? (a) Round, (b) flat, (c) hyperbolic, (d) some other, (e) no way to know ( $N=265)$.

\begin{tabular}{|c|c|c|c|c|c|c|}
\hline & Round & No shape & Expanding & Infinite & Open & IDK/NSR/NR \\
\hline Round objects & 2 & 0 & 0 & 0 & 0 & 0 \\
\hline Authority & 5 & 0 & 0 & 0 & 0 & 0 \\
\hline Observations & 4 & 0 & 2 & 0 & 0 & 0 \\
\hline Big Bang & 1 & 0 & 1 & 0 & 0 & 0 \\
\hline We don't know & 0 & 1 & 0 & 0 & 0 & 0 \\
\hline IDK/NSR/NR & 1 & 1 & 1 & 1 & 1 & 3 \\
\hline
\end{tabular}

FIG. 5. Heat map highlighting relationships between ASTRO 101 students' ideas on the shape or geometry with their responses to How do we know? $(N=16)$ Each cell specifies the number of responses coded with a particular combination of shape and reasoning.

- In both $\mathrm{Q} 1$ and $\mathrm{Q} 2$, students who described the Universe as round often described round objects in the Universe or reasoned that the Universe was round because objects in the Universe are round (Q1 20\%, Q2 26\%). Many incorrectly cited the big bang theory or an explosion from a central point (Q1 10\%, Q2 $11 \%)$. However, the most popular reasoning for a round Universe was an appeal to authority such as having seen or heard it before (Q1 50\%, Q2 14\%) or because "it seemed like the right answer" (Q2 30\%).

- Students who chose flat or hyperbolic for the curvature of the Universe in Q2 most often cited an appeal to authority as the reasoning for their choice. Neither of these scenarios came up in the open-response version of the question.

- When choosing some other shape, students most often did not provide details on a specific shape $(47 \%)$ or described an elliptical or oval shape (27\%). Again, these choices were most often justified by an appeal to authority, such as "diagrams I have seen."

We know from decades of educational research that novices and experts often have different understandings of scientific vocabulary [3,22]; an open-ended question (Q3) probed the potential differences about curvature. More than a third of students (36\%) either responded I don't know or did not respond to this question. Figure 7 shows the remaining responses by frequency. The most popular theme (30\%) included descriptions of properties of the Universe, such as the dimensions, shape, angles, size, area, distance, or amount of bend. The next most popular response type (22\%) described these properties, but for objects in the Universe. A sizable fraction (15\%) also described a gravitational lensing scenario, where massive objects bend the fabric of space. Some students specified a shape for the Universe (7\%), the most popular of which was round $(60 \%)$.

In addition to the most frequent responses in Fig. 7, we also want to draw attention to the formation theme, which arose because of ambiguity in the way students used the word formation compared to how astronomers use it. When speaking of formation, especially in the context of cosmology, astronomers mean how structures and systems have evolved to their present state. Students, however, may use the word to describe an arrangement or placement of 


\begin{tabular}{|l|c|c|c|c|c|c|}
\cline { 2 - 7 } \multicolumn{1}{c|}{} & $\begin{array}{c}\text { No way to } \\
\text { know }\end{array}$ & Round & Hyperbolic & Flat & Other & No response \\
\hline Big Bang & 0 & 8 & 4 & 0 & 0 & 1 \\
\hline Objects in U & 1 & 20 & 3 & 5 & 3 & 0 \\
\hline Authority & 2 & 11 & 17 & 9 & 6 & 0 \\
\hline Because it is & 9 & 23 & 15 & 3 & 2 & 0 \\
\hline I don't know & 18 & 3 & 5 & 4 & 1 & 0 \\
\hline Don't know yet & 20 & 1 & 0 & 0 & 0 & 0 \\
\hline No way to know & 24 & 1 & 0 & 0 & 0 & 0 \\
\hline Infinite U & 30 & 0 & 2 & 3 & 1 & 0 \\
\hline Expanding U & 7 & 5 & 2 & 1 & 1 & 0 \\
\hline NR/NSR/IRR & 1 & 10 & 2 & 4 & 2 & 2 \\
\hline
\end{tabular}

FIG. 6. Heat map highlighting the relationships between ASTRO 101 students' selection of the geometry or curvature of space with their responses to Why did you select the answer you chose? $(N=265)$. Each cell specifies the number of responses coded with a particular combination of curvature and reasoning.

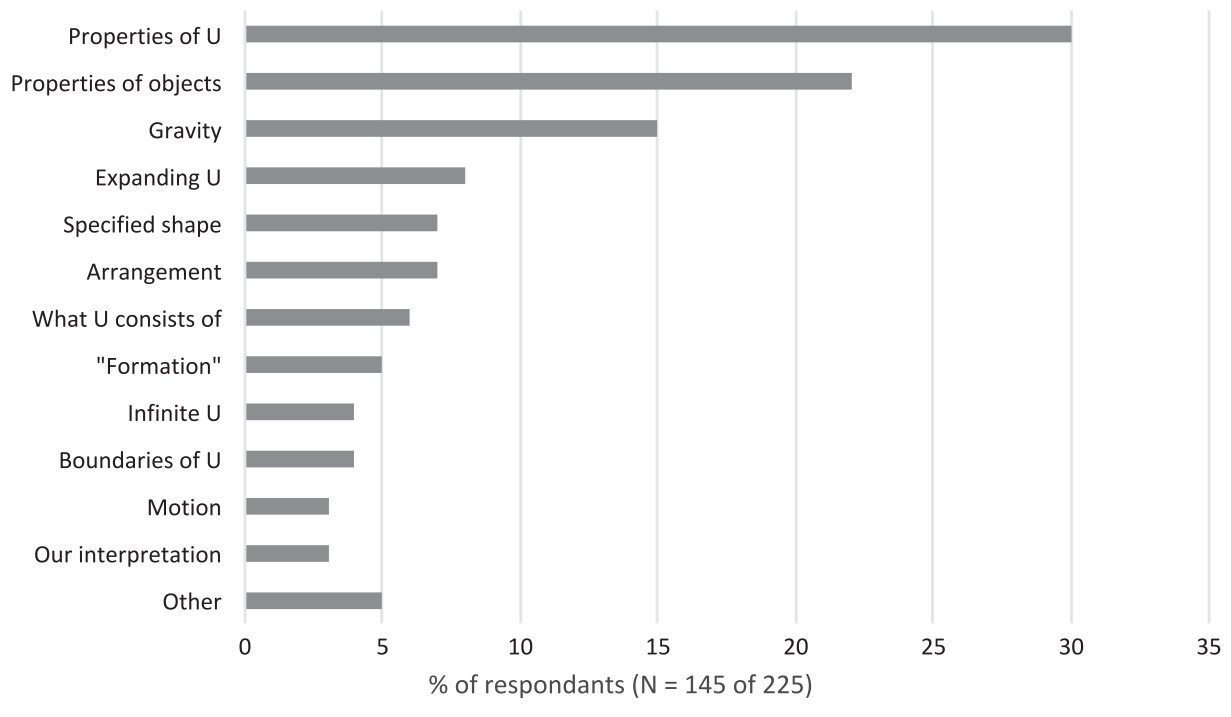

FIG. 7. ASTRO 101 Preinstruction survey responses for What do astronomers mean when they talk about the "shape" or "curvature" of space (the Universe)? ${ }^{6}$

systems as opposed to how systems evolve. Indeed, in other sciences, formation may refer to a structure, such as a rock formation; in everyday life, formation may refer to a grouping or arrangement, such as a marching band being in formation. In our preinstruction surveys, students say, for

\footnotetext{
${ }^{6}$ Universe is abbreviated " $U$ " in the figure.
}

example, that the "shape and curvature of space consists of the formation of planets and stars in the space (Universe)" or that the shape is "the formation of galaxies measured by their distances from one another," or "the way all the galaxies formulate $[s i c]$ within the Universe." We therefore separated the responses that ambiguously used the word formation into their own code. 


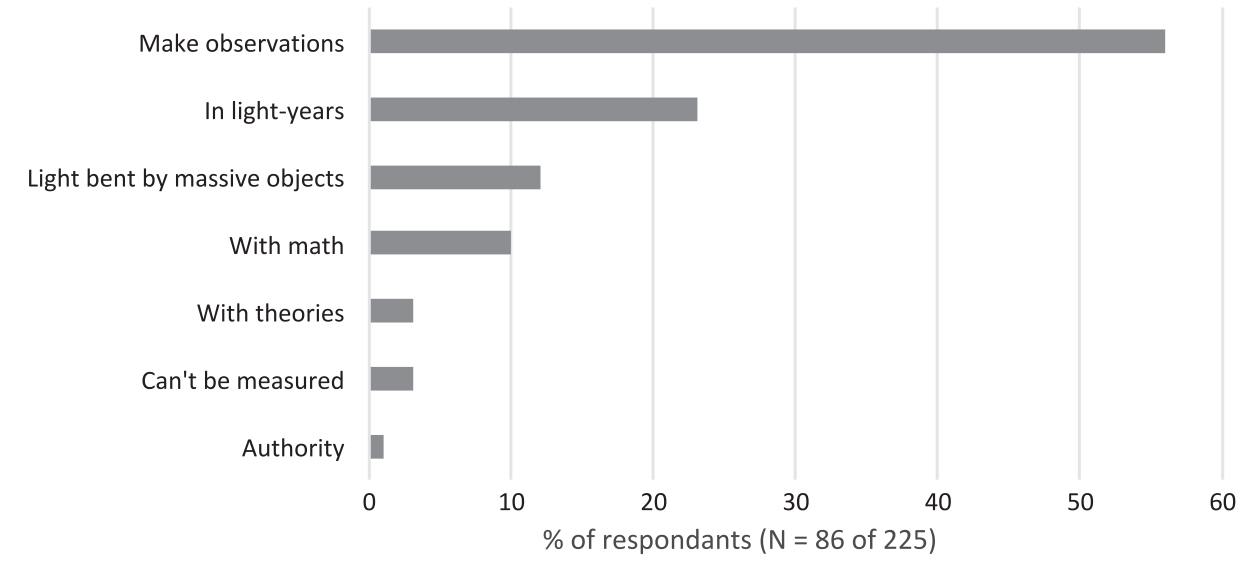

FIG. 8. ASTRO 101 Preinstruction survey responses for How do they measure this trait?

As a follow-up to the question of what astronomers mean by the shape or curvature of the Universe, we asked students how astronomers measure this trait. The majority $62) \%$ ) of students did not respond to the question or responded I don't know. Of those who did respond, more than half (56\%) said we know by making observations. This theme included responses such as looking at objects, from light, with telescopes or satellites, or other similar descriptions. These results are similar to our findings for Q1(b). About a quarter of students (23\%) said the curvature is measured in light years, with no further description; a fraction gave an argument related to observing gravitational lensing (13\%); and a small number insisted that it cannot be measured $(5 \%)$. The full breakdown of responses by frequency is shown in Fig. 8.

\section{B. Postinstruction exams: The CMB and the curvature of the Universe}

The results of the multiple-choice exam question give hints to students' postinstruction ideas about the curvature of the Universe. ASTRO 101 students at CSU were asked the question during the last week of classes. The students had one minilecture (including Fig. 1) and one homework on the curvature of space, as part of their cosmology unit, prior to taking the exam. Note that here we have described the relevant curriculum materials to provide context for the environment in which the development of students' ideas has taken place, not to measure the effectiveness of the curriculum.

Postinstruction, we found that the most popular choice (53\%) for the curvature of the Universe is now zero, the value measured by scientists. Still, more than a quarter of students $(28 \%)$ chose a spherical geometry and a handful $(11 \%)$ responded that the data were not good enough to tell. The results are summarized in Fig. 9.

As described in Sec. II, we put a map of the CMB in one of two different styles on the exam, elliptical or rectangular, to try to determine if students' responses might be affected by different visualizations. The maps were not used for the question on curvature, but for a different question about the $\mathrm{CMB}$ on the exam. At first glance, it appears that the style

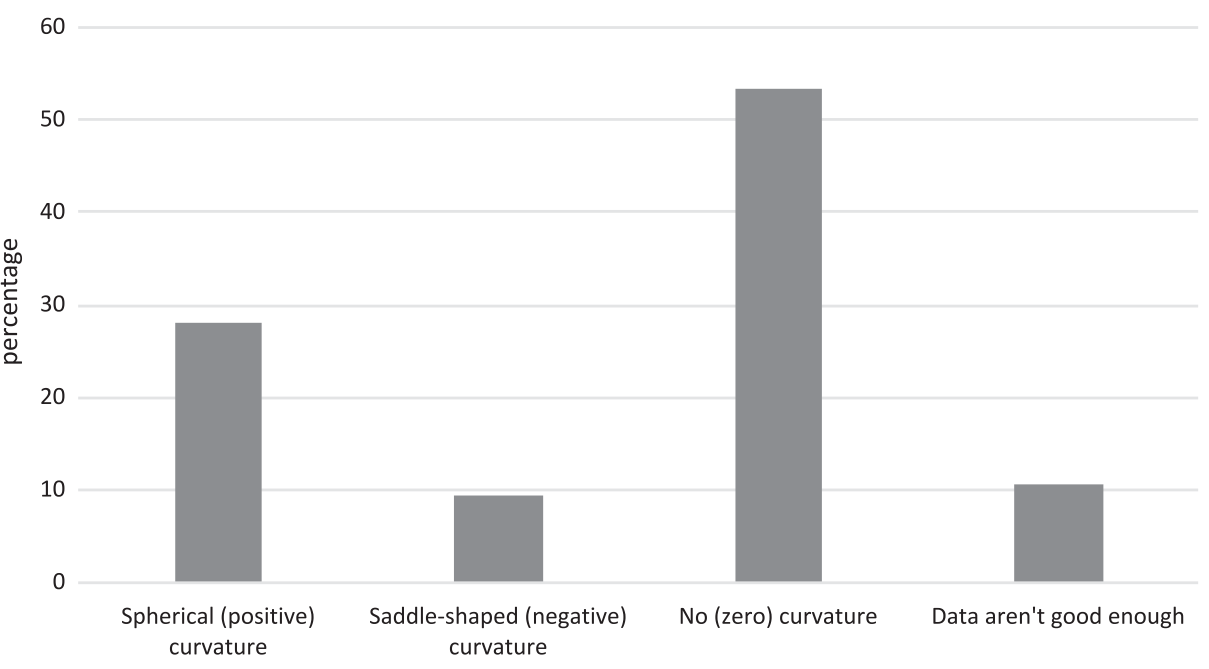

FIG. 9. ASTRO 101 Preinstruction survey responses for What does the cosmic microwave background tell us about the overall curvature of the Universe? $(N=75)$. 


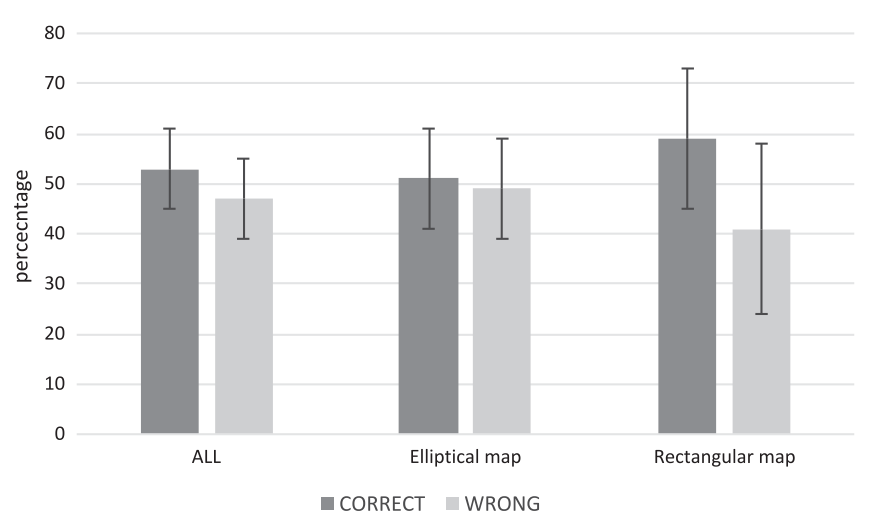

FIG. 10. Students' responses to the question of the curvature of space were examined to determine if they were influenced by an elliptical $(N=53)$ or rectangular $(N=22)$ map of the CMB on a postinstruction exam.

of map (i.e., rectangular or elliptical) may influence students' responses (Fig. 10). However, an independent $t$ test shows that there is not a statistically significant difference $(p=0.199)$. A follow-up survey with a larger number of responses over multiple institutions would allow us to be more confident in our answer to this question.

\section{Interviews}

In interviews, nine ASTRO 101 students from CSU described their thoughts on the shape of the Universe. Three students were interviewed preinstruction and six were interviewed postinstruction. Four of the students interviewed postinstruction also spoke of their preinstruction ideas; those ideas are grouped with the results from other preinstruction interviews, for a total of $N=7$. Students' responses were coded thematically for shape; a summary is presented in Fig. 11. The interviews were intended to provide exemplifications of students' ideas on the shape of the Universe before and after instruction. Indeed, many of the themes seen in interviews are similar to those seen in the surveys, including the popular

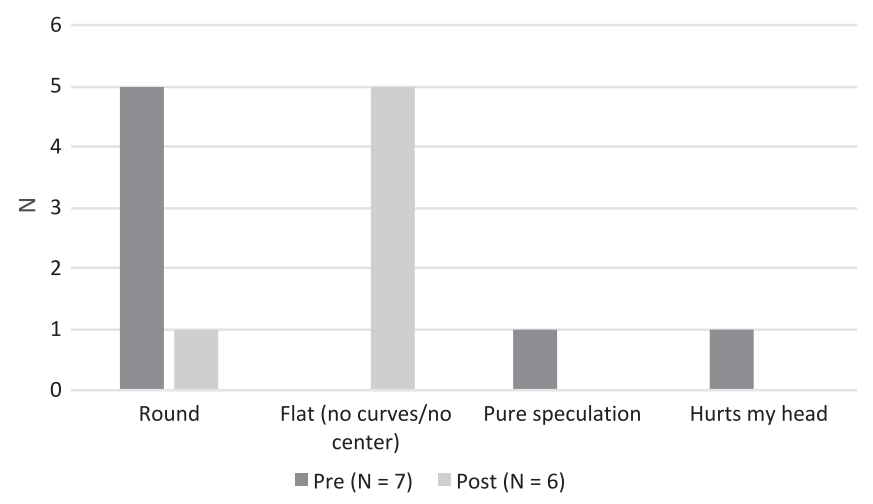

FIG. 11. Shape of the Universe as described by students in interviews. preinstruction idea that the Universe is round and a shift to postinstruction of primarily describing the Universe as flat.

In interviews addressing their preinstruction ideas, five of the seven students interviewed described the Universe as round, with reasoning as described below. While less popular postinstruction, one student out of six interviewed still described the Universe as round.

As seen in our preinstruction survey data, students in interviews draw on knowledge of objects in the Universe to support their idea that the Universe is round. In a preinstruction interview, Student No. 2 elaborates:

"The Universe is like a big never-ending ball kind of with a million different things ... a ball seems round. When you look into outer space, doesn't it look like [it's] roundish? ... It doesn't look like a box. I just assumed it was round. The Sun is round, the moons are round, planets are round, stars are roundish. I just assumed [the Universe] was round too."

Students also draw on the common, but incorrect, idea that the big bang theory describes an explosion from a central point $[12,24,37]$ as reasoning for why they think the Universe is round. As Student No. 1 explains in a preinstruction interview:

"Everything in this whole Universe came from some type of like a hot, seem like a hot dense ball, I believe, and it exploded."

Student No. 3 explains in a postinstruction interview how their ideas have changed since taking ASTRO 101:

"I thought it was a giant sphere, that was sort of going out from the point of the big bang in a-in a sphere. I thought that's what the prevailing view was. Since taking this class, um I've come to understand that the Universe has no center and has no boundaries..."

The themes, seen in precourse surveys, that there is no way to measure the curvature or that I don't know also came up in interviews. When speaking about the shape of the Universe, Student No. 9 said that prior to instruction,

"I would imagine it was just speculation.... everything I've ever seen about talking about the shape of the Universe was pure speculation."

Student No. 7 said,

"I really didn't give that much thought as to how the Universe was really shaped, 'cause that would just hurt my head."

Gravitational lensing was another popular preinstruction theme for the curvature of space seen in surveys. This was 
also seen in a preinstruction interview, where Student No. 8 described the curvature of space around objects:

"What I think of is like a sheet of something... that easily bends and like as objects kind of sit on top of that ... space is going to kind of curve around those objects like those objects distort, you know, space."

On postinstruction exams, students most often correctly describe the Universe as flat, although the idea that it is round persists for some students. Similarly, in the six postinstruction interviews, five students described a flat Universe and one described a round Universe. For example, Student No. 7 describes the shape,

"I'm looking at it like a long, like a really, really long rectangle like, it's really, really rectangular, you know what I mean. Um I say like a big um, like a big piece of paper that keeps spreading like over time... like some spandex almost, um-like a square shaped spandex just keep going in different directions."

In postinstruction interviews, two of the six students mentioned that they learned about the possibility of a saddle-shaped curvature in lecture, but said zero curvature was the correct description. As Student No. 6 describes,

"I think I chose [zero curvature]... I was battling between is it saddle because we had notes on that, the saddle shape, but I think they found that there is no curvature, right? I bounce between, because I know we had some in-depth lecture on that."

In postinstruction interviews, students are aware of specific measurements of the curvature and no students say it cannot be measured. Two students describe the process by which we compare measurements of the CMB to models to determine the curvature of the Universe. For example, Student No. 5 states how we know the Universe is flat,

"Well thanks to your uh work, along with your colleagues ${ }^{7}$ we know that it's flat, so um. I believe that's we spoke about, like it being flat overall versus saddle shape."

Student No. 9 says,

"From what I've seen and learned, especially in this class is that, the cosmic microwave background is the real teller to exactly what the shape could possibly be. If you compare [the $C M B$ ] that we actually see in the Universe to ... different shapes, then you actually can determine which one is more like the real Universe. Before that, I would imagine it was just speculation."

${ }^{7}$ K. C. was also a member of the BOOMERANG Collaboration.
However, that student still describes the Universe as round:

$$
\begin{aligned}
& \text { "It's three dimensional and it's never ending. You're } \\
& \text { just going around in a never-ending circle..." }
\end{aligned}
$$

\section{DISCUSSION}

Through preinstruction surveys, a postinstruction exam question, and interviews, we have probed ASTRO 101 students' ideas about the curvature of the Universe. The emergent nature of our thematic coding meant that the data drove the process, rather than us choosing a broad coding scheme $a$ priori that would be applied consistently across every data source. We noticed some differences in the fraction of particular responses that might be influenced by how the question is asked, in a form of priming [51]. Some response themes are seen across questions, instrument type, and institutions. For example, the round theme came up in all question formats, whether open ended, multiple choice, or interview. A multiple-choice question, however, primed for terms that were not used by students in the open-ended question, such as flat and hyperbolic. Here we discuss some of the trends that emerged from our data, organizing around common themes seen in multiple data sources.

Finding 1: Prior to instruction, students think the Universe is round

One of the most prominent (but perhaps not surprising to instructors of this topic) trends seen in our data is students' preinstruction idea that the Universe is round. Here we use round to describe student responses such as "circular," "spherical," "having a central point," or literally "round." (Note in a study of the shape of Earth, Nussbaum and Novak [52] found that young students used "round" in several different ways, only one of which is spherical. In our study, we do not know exactly what most participants had in mind, given that we were not able to ask students to elaborate on written responses that might use this term.) This description as round lies in contrast to the scientific consensus that the curvature of the Universe is zero (as opposed to positive, which would indicate a spherical curvature). In an open-response preinstruction survey question (Q1, $N=16), 63 \%$ of students described the Universe as round. In a multiple-choice question (Q2, $N=265$ ), $29 \%$ of students chose round from among five possible choices. Furthermore, in Q2, of the 15 students who chose other for the curvature, 27\% described the Universe as elliptical or oval shaped. We also see in Q3(a) $(N=225)$ that, of the 10 students that specified the Universe's shape, $60 \%$ described it as round. In interviews, five of seven students described the Universe as round preinstruction. In this study, we found that students gave three main reasons for describing the Universe as round, as follows. 
Finding la: Students draw on knowledge of round objects in the Universe

Of the students who described the Universe as round in response to preinstruction survey questions and preinstruction interviews, a sizable fraction referred to round objects or round systems in the Universe in their reasoning (Q1 20\%, Q2 26\%, 2 of 5 interviews). Some students may be extrapolating their ideas about smaller objects to the entire Universe. For example, in a preinstruction interview, Student No. 2 described this type of reasoning. On preinstruction surveys, responses included: "The planets orbit the sun and galaxies are also rounded into a spiral so the Universe is probably round," and "Everything pretty much in our Universe reflects a round shape. That is why I believe it could be spherical." Some students may be conflating those smaller objects with the Universe itself, influenced by the known confusion between the terms galaxy, solar system, and Universe as seen in Refs. [26,30,53]. Survey examples include responses such as follows: "Because I'm pretty sure the Earth is round," "The original thought behind the world was that it was flat until Christopher Columbus discovered that it is actually round," "Because [of] the circulation of planets," and "That's the way the planets are arranged." Likewise, in a preinstruction interview, Student No. 4's response is a combination of these ideas: "I would assume just because like the Sun looks round and the planets are round, then, of course universe, the galaxies are round."

Finding 1b: Students draw on the common, but incorrect, idea that the big bang theory describes an explosion from a central point

Studies on students' ideas about the big bang theory have consistently shown that a majority of students think the big bang theory describes an explosion from a central point $[12,24,37]$. In this study, we see that a sizable number of students use this incorrect idea to reason that the Universe must be round (Q1 10\%, Q2 11\%, 2 of 5 interviews). For example, in interviews, Student No. 1 described the Universe as a hot, dense ball that exploded and Student No. 3 described a sphere going out from a central point. Examples of responses to the preinstruction surveys included reasoning such as "The universe is roughly globe like, constantly expanding. Using the big bang theory, the explosion sent all sorts of matter in all directions," "During the big bang, it would've been blown up in a spherical shape" and "The big bang expanded in all directions, spherically."

\section{Finding 1c: Students appeal to authority}

Students who draw on their knowledge of round objects or of the big bang theory, though incorrect, are using physical reasoning to explain the curvature. However, other popular justifications for a round Universe in preinstruction surveys were appeals to authority (Q1 50\%, Q2 14\%) or because it is (30\% Q2). Appeals to authority in the preinstruction surveys included justifications such as
"I feel like I've learned that it is round," "Because this is what I have learned in my earlier years of schooling," and "Models I have seen." Responses classified as because it is included, for example, "Because it is my best guess," "It sounds correct," and "Cause I know."

Finding 2: Prior to instruction, students are less likely to choose a flat or hyperbolic curvature and those who do are unlikely to employ physical reasoning

In open-ended preinstruction survey questions and interviews, students did not mention flat or hyperbolic curvatures, which are two other candidates historically considered by astronomers. Even in the multiple-choice preinstruction survey question, hyperbolic, flat, and other combined only accounted for about a third of responses $(17 \%, 10 \%$, and $6 \%$, respectively). In all three groups students primarily employed nonphysical reasoning to justify their choice as follows: hyperbolic (authority $38 \%$; because it is 33\%; no response 15\%), flat (authority $33 \%$; because it is $11 \%$; no response 15\%), other (authority 40\%; because it is 13\%; no response 13\%). For example, students said the term hyperbolic sounded familiar from math class, declared that the Universe "isn't quite round," said that flatness "sounded most logical" or "I thought I heard my professor talk about flatness."

Finding 3: Prior to instruction, students are skeptical that the curvature can be measured

Preinstruction, many students say that there is no way to measure the curvature of the Universe, even though scientists have been able to measure this quantity to high precision for almost two decades. How frequently this response manifests depends on how we ask the question. When students are primed to think the curvature is measurable, as seen in survey questions Q1(b) asking how we know or Q3(b) asking how astronomers measure the curvature, students who responded often said we "make observations" (Q1b 31\%, Q3b 56\%). These students may be aware that astronomers make observations using telescopes, but they do not describe specifics, such as defining what exactly is being observed or how that leads to a measurement of the curvature. Though a majority of students (62\%) did not respond to Q3(b), a small percentage $(5 \%)$ of students who responded still insisted that the curvature can't be measured.

When students are primed to think the curvature is not measureable (e.g., multiple-choice survey question Q2(a) included no way to know as an option), students select this as the most popular choice (37\%). The most popular reasoning for this is because the Universe is too big or infinite (30\%). This is similar to what was seen in our prior work, where $24 \%$ of students said that distances of or in the Universe could not be measured [26]. In addition, a number of students chose the response no way to know for the curvature not because they truly believe there is no way to know, but because they thought we do not yet know, we do not have the technology to know, or because they 
themselves did not know. These types of responses were also seen in preinstruction interviews: Student No. 9 imagined that the curvature of the Universe was a matter of "speculation," and Student No. 6 had not given it much thought.

Hansson and Redfors [54], in their study of lower secondary students' ideas about astrobiology, found that participants expressed different views depending upon whether the question was posed about their ideas or about the ideas scientists hold. Lombardi, Sinatra, and Nussbaum [55] used a scale that asked students to rate the degree of agreement climate scientists would have with certain statements. They note that, particularly for a topic with perceived controversy, "using a scale measuring the level of agreement with climate scientists allowed us to gauge understanding of scientific explanation, not acceptance of or attitudes toward scientific explanations" (p. 54). This difference between students' own ideas and their understanding of scientific explanations may be at play in our study as well, although further research is needed here. An application of Hansson and Redfors' [54] method might be particularly interesting.

Finding 4: Students' ideas on the meaning of the term curvature were similar to, but broader than, its cosmological usage

In response to a preinstruction survey question probing the meaning of the term curvature, the majority of students responding said that astronomers use the term to describe properties, such as the dimensions, shape, angles, size, area, distance, or amount of bend. This is similar to how scientists use the term and can be seen as a resource that students bring to the classroom from their prior experiences with geometry. Students who described curvature in this way used it either in reference to the entire Universe (30\% of respondents), as cosmologists would, or in reference to objects in the Universe (22\%), in a somewhat broader way than cosmologists would. Student No. 9, when asked what astronomers mean when they talk about the shape or curvature of the Universe in postinstruction interview, gives a clear explanation, consistent with scientific usage:

"When I think about when astronomers talk about the shape of the Universe, everything we see has a shape. Basically, they are talking about, I believe that they are talking about the simplest of shapes, whether it be round, square, rectangular, octagonal, whatever."

While we have explored how students think astronomers define the term curvature, it would also be interesting to explore how the ideas students hold compare to the ideas students think astronomers hold about what the curvature of the Universe is, using the method of Hansson and Redfors [54].

Finding 5: Correct ideas on gravitational lensing are a resource students bring to the classroom
Gravitational lensing was another popular preinstruction theme for the curvature of space. Fifteen percent of the students responding to the preinstruction survey Q3 described gravity as curving or bending the fabric of space near massive objects. This was also seen in a preinstruction interview.

Although students responding in this way described the bending of space near objects rather than the Universe as a whole, it is encouraging that students brought this correct idea about general relativity to the classroom, which might be leveraged as a resource in the learning process.

Finding 6: After instruction, students are more likely to correctly describe the Universe as flat

On the multiple-choice postinstruction exam question, a majority (53\%) of students chose zero curvature. Similarly, in the six postinstruction interviews, five students described a flat Universe.

However, the idea that the Universe is round persists for some students. On the exam question, students chose spherical (positive) curvature $28 \%$ of the time, the second most popular response. Out of six postinstruction interviews, one student persisted in describing a round Universe.

The idea that we don't know the curvature of the Universe seems less likely postinstruction. In response to the postinstruction exam question on what measurements of the CMB tell us about the curvature of the Universe, $11 \%$ of students chose the response the data is not yet good enough to tell. In postinstruction interviews, students are aware of specific measurements of the curvature and no students say it cannot be measured.

Finding 7: Priming with differently shaped maps of the $C M B$ on an exam does not appear to affect students' responses

As cosmological visualizations become ubiquitous in the scientific community and in the classroom, the effect of visualizations on students' ideas about the curvature of the Universe and other cosmological topics is becoming an increasingly important avenue of research. For example, Buck [14] found that novice learners are better able to identify dark matter in visualizations of large-scale structure when it is colorized using a dark color. Eriksson and colleagues [56] identify an anatomy of disciplinary discernment, a "hierarchy of what is focused on and how it is interpreted in an appropriate, disciplinary manner." They report a relationship between educational attainment and degree of disciplinary discernment for participants viewing and describing a fly-through simulation on Galactic and extragalactic distance scales. In other words, novices "see" visualizations quite differently than experts. However, unlike findings by Buck [14] and Eriksson and colleagues [56], we did not find that visualizations (i.e., elliptical versus rectangular maps of the $\mathrm{CMB}$ on a postinstruction exam) had an effect on students' responses and ideas about the curvature of the Universe. 


\section{CONCLUSIONS}

Powerful observations and advances in computation and visualization have led to a new era of precision cosmology, in which astronomers can empirically answer fundamental questions about the nature of the Universe. In this exploratory study, we used preinstruction surveys, a postinstruction exam question, and pre- and postinstruction interviews to explore students' ideas about one of those fundamental questions: what is the curvature of the Universe? Astronomers have measured the curvature to be zero to high precision, but, as indicated by our results, this information has not been made clear to undergraduate students prior to taking ASTRO 101.

Our major findings on students' pre- and postinstruction ideas, supported by multiple data sources, include the following:

(1) Prior to instruction, students think the Universe is round. In support of this idea:

(a) Students draw on knowledge of round objects in the Universe.

(b) Students draw on the common, but incorrect, idea that the big bang theory describes an explosion from a central point.

(c) Students appeal to authority.

(2) Prior to instruction, students are less likely to choose a flat or hyperbolic curvature and those who do are unlikely to employ physical reasoning.

(3) Prior to instruction, students are skeptical that the curvature can be measured.

(4) Students' ideas on the meaning of the term curvature were similar to, but broader than, its cosmological usage.

(5) Correct ideas about gravitational lensing are a resource students bring to the classroom.

(6) After instruction, students are more likely to correctly describe the Universe as flat.

We also explored how verbal priming (how we ask the question) or visual priming (with cosmological images) affects students' responses. We noticed that verbal priming appeared to have some effect on the fraction of different types of responses elicited from students, such as the fraction of students describing the Universe as round, the fraction of students expressing skepticism that the curvature of the Universe can be measured, and whether students responded flat or hyperbolic in describing the curvature of the Universe.

The area of cosmological visualizations holds obvious importance for educators working to convey an understanding of the Universe. Indeed, in our preinstruction surveys, many students justified their ideas about the curvature of the Universe with appeals to authority that included viewing diagrams or seeing something on TV or in a class. While we are not evaluating our curriculum, and our postinstruction results suggest that students are more likely to correctly describe the Universe as flat postinstruction, we do find that the idea of a round Universe persists in some students. This persistence is potentially because the course does not heavily focus on this topic. The incorrect idea that the Universe is round might also be reinforced or mitigated depending on which visualizations and demonstrations an instructor chooses to employ as students progress through a course. Visualizations, including elliptical projections of CMB anisotropy maps, have the potential to perpetuate the belief that the Universe is round. Additionally, a classic classroom demonstration of the expansion of the Universe using a balloon (or other near-spherical objects) could fortify the belief that the Universe is round. At CSU, we instead used, and recommend using, a stretchy rubber physical therapy band with pictures of galaxies stapled to it, in which the band itself (representing space) can be stretched in three directions without reinforcing the incorrect ideas that the Universe is round and expands spherically.

In our study, we did not see a difference between correct and incorrect responses to a postinstruction multiple-choice question after priming with an elliptical or rectangular map of the CMB, but we did not explicitly investigate how students interpreted such images. As well as asking the questions described in this study to a greater number and range of students before, during, and after instruction, it may also be fruitful to ask students to choose among pictoral representations of the curvature of the Universe, both on surveys and in interviews, and to explicitly ask students to describe what they are "seeing" in different maps of the CMB. While we find no evidence that the shape of a $\mathrm{CMB}$ visualization included on the exam impacted how students respond, more research will be crucial for determining exactly how such visualizations impact student understanding of difficult cosmological concepts.

\section{ACKNOWLEDGMENTS}

This work was supported by NASA Grant No. NNX10AC89G and by the Education and Public Outreach program for NASA's Fermi Gamma-ray Space Telescope, the Illinois Space Grant Consortium, and NSF CCLI Grant No. 0632563 at CSU. This work would not have been possible without the participation of students from CSU, CU, and UNLV. 
[1] American Association for the Advancement of Science, Science for All Americans (Oxford University Press, New York, 1990).

[2] AAAS, Benchmarks for Science Literacy (Oxford University Press, New York, 1993).

[3] J. D. Bransford, A. L. Brown, and R. R. Cocking, How People Learn: Brain, Mind, Experience, and School (expanded edition) (National Academy of Sciences, Washington, DC, 2000), p. 342.

[4] M. A. Fox and N. Hackerman, Evaluating and Improving Undergraduate Teaching in Science, Technology, Engineering, and Mathematics (National Academies Press, Washington, DC, 2003).

[5] National Research Council, National Science Education Standards (National Academies Press, Washington, DC, 1996).

[6] NRC, Learning and Understanding: Improving Advanced Study of Mathematics and Science in U.S. High Schools (National Academies Press, Washington, DC, 2003).

[7] NRC, A Framework for K-12 Science Education: Practices, Crosscutting Concepts, and Core Ideas (National Academies Press, Washington, DC, 2012).

[8] M. S. Donovan and J. D. Bransford, How Students Learn: Science in the Classroom (National Academies Press, Washington, DC, 2005).

[9] J. M. Bailey and T.F. Slater, A review of astronomy education research, Astron. Educ. Rev. 2, 20 (2003).

[10] A. Lelliott and M. Rollnick, Big ideas: A review of astronomy education research 1974-2008, Int. J. Sci. Educ. 32, 1771 (2010).

[11] L. Hansson and A. Redfors, Swedish upper secondary students' views of the origin and development of the universe, Res. Sci. Educ. 36, 355 (2006).

[12] E. E. Prather, T. F. Slater, and E. G. Offerdahl, Hints of a fundamental misconception in cosmology, Astron. Educ. Rev. 1, 28 (2002).

[13] C.S. Wallace, An investigation into introductory astronomy students' difficulties with cosmology, and the development, validation, and efficacy of a new suite of cosmology lecture-tutorials, Ph.D. dissertation, University of Colorado Boulder, 2011.

[14] Z. Buck, The effect of color choice on learner interpretation of a cosmology visualization, Astron. Educ. Rev. 12, 010104 (2013).

[15] U. Eriksson, Reading the sky: From starspots to spotting stars, Ph.D. dissertation, Uppsala University, 2014.

[16] J. M. Pasachoff, What should college students learn? Phases and seasons? Is less more or is less less?, Astron. Educ. Rev. 1, 124 (2002).

[17] P. de Bernardis et al., A flat universe from high-resolution maps of the cosmic microwave background radiation, Nature (London) 404, 955 (2000).

[18] Planck Collaboration, Planck 2015 results. XIII. Cosmological parameters, Astron. Astrophys. 594, A13 (2016).

[19] J. A. Dole and G. M. Sinatra, Reconceptalizing change in the cognitive construction of knowledge, Educ. Psychol. 33, 109 (1998).

[20] G. J. Posner, K. A. Strike, P. W. Hewson, and W. A. Gertzog, Accommodation of a scientific conception:
Toward a theory of conceptual change, Sci. Educ. 66, 211 (1982).

[21] A. E. Lawson, The acquisition of biological knowledge during childhood: Cognitive conflict or tabula rasa?, J. Res. Sci. Teach. 25, 185 (1988).

[22] R. Driver and J. Easley, Pupils and paradigms: A review of literature related to concept development in adolescent science students, Stud. Sci. Educ. 5, 61 (1978).

[23] J. L. Lemke, Articulating communities: Sociocultural perspectives on science education, J. Res. Sci. Teach. 38, 296 (2001).

[24] P. R. Pintrich, R. W. Marx, and R. A. Boyle, Beyond cold conceptual change: The role of motivational beliefs and classroom contextual factors in the process of conceptual change, Rev. Educ. Res. 63, 167 (1993).

[25] K. A. Strike and G. J. Posner, A revisionist theory of conceptual change, in Philosophy of Science, Cognitive Psychology, and Educational Theory and Practice, edited by R. A. Duschl and R. J. Hamilton (State University of New York, New York, 1992), p. 147.

[26] K. Coble, C. T. Camarillo, L. E. Trouille, J. M. Bailey, G. L. Cochran, M. D. Nickerson, and L. R. Cominsky, Investigating student ideas about cosmology I: Distances and structure, Astron. Educ. Rev. 12, 010102 (2013).

[27] K. Coble, M. D. Nickerson, J. M. Bailey, L. E. Trouille, G. L. Cochran, C. T. Camarillo, and L. R. Cominsky, Investigating student ideas about cosmology II: Composition of the universe, Astron. Educ. Rev. 12, 010111 (2013).

[28] M. Conlon, K. Coble, J. M. Bailey, and L. R. Cominsky, Investigating student ideas about the fate of the Universe, Phys. Rev. Phys. Educ. Res. 13, 020128 (2017).

[29] L. E. Trouille, K. Coble, G. L. Cochran, J. M. Bailey, C. T. Camarillo, M. D. Nickerson, and L. R. Cominsky, Investigating student ideas about cosmology III: Big bang theory, expansion, age, and history of the Universe, Astron. Educ. Rev. 12, 010110 (2013).

[30] J. M. Bailey, K. Coble, G. L. Cochran, D. M. Larrieu, R. Sanchez, and L. R. Cominsky, A multi-institutional investigation of students' preinstructional ideas about cosmology, Astron. Educ. Rev. 11, 010302 (2012).

[31] J. M. Bailey, E. E. Prather, B. Johnson, and T. F. Slater, College students' preinstructional ideas about stars and star formation, Astron. Educ. Rev. 8, 010110 (2009).

[32] E. G. Offerdahl, E. E. Prather, and T. F. Slater, Students' preinstructional beliefs and reasoning strategies about astrobiology concepts, Astron. Educ. Rev. 1, 5 (2002).

[33] R. Duit and D. F. Treagust, Conceptual change: A powerful framework for improving science teaching and learning, Int. J. Sci. Educ. 25, 671 (2003).

[34] A. Einstein, Die grundlage der allgemeinen relativitätstheorie, Ann. Phys. (Paris) 354, 769 (1916).

[35] W. Hu and S. Dodelson, Cosmic microwave background anisotropies, Annu. Rev. Astron. Astrophys. 40, 171 (2002).

[36] A. Doroshkevich, Y. B. Zel'dovich, and R. Syunyaev, Fluctuations of the microwave background radiation in the adiabatic and entropic theories of galaxy formation, Sov. Astron. 22, 523 (1978). 
[37] M. Kamionkowski, D. N. Spergel, and N. Sugiyama, Small-scale cosmic microwave background anisotropies as probe of the geometry of the universe, Astrophys. J. 426, L57 (1994).

[38] L. Anderson et al., The clustering of galaxies in the SDSSIII baryon oscillation spectroscopic survey: Baryon acoustic oscillations in the data releases 10 and 11 galaxy samples, Mon. Not. R. Astron. Soc. 441, 24 (2014).

[39] A. Lewis and S. Bridle, Cosmological parameters from CMB and other data: A Monte Carlo approach, Phys. Rev. D 66, 103511 (2002).

[40] A. Lewis and A. Challinor, Weak gravitational lensing of the CMB, Phys. Rep. 429, 1 (2006).

[41] A. Lewis, A. Challinor, and A. Lasenby, Efficient computation of cosmic microwave background anisotropies in closed Friedmann-Robertson-Walker models, Astrophys. J. 538, 473 (2000).

[42] J. W. Creswell and V.L. Plano Clark, Designing and Conducting Mixed Methods Research, 2nd ed. (Sage Publications, Thousand Oaks, CA, 2011).

[43] R. J. Beichner, An introduction to physics education research, in Getting started in PER: Reviews in PER, edited by C. Henderson and K. A. Harper (American Association of Physics Teachers, College Park, MD, 2009).

[44] J. Kregenow, M. Rogers, and M. Constas, Multidimensional education research: Managing multiple data streams, Astron. Educ. Rev. 9, 010104 (2010).

[45] B. Partridge and G. Greenstein, Goals for 'Astro 101': Report on Workshops for Department Leaders, Astron. Educ. Rev. 2, 46 (2003).
[46] T. F. Slater, J. P. Adams, G. Brissenden, and D. Duncan, What topics are taught in introductory astronomy courses?, Phys. Teach. 39, 52 (2001).

[47] S. Stemler, An overview of content analysis, Practical Assess. Res. Eval. 7 (2001), http://PAREonline.net/getvn .asp? $\mathrm{v}=7 \& \mathrm{n}=17$.

[48] J. W. Creswell, Qualitative Inquiry and Research Design: Choosing among Five Traditions, 2nd ed. (Sage Publications, Thousand Oaks, CA, 2007).

[49] K. L. Gwet, Handbook of Inter-Rater Reliability, 3rd ed. (Advanced Analytics, Gaithersburg, MD, 2012).

[50] E. M. Nussbaum, Categorical and Nonparametric Data Analysis: Choosing the Best Statistical Technique (Routledge, New York, NY, 2015).

[51] R. J. Sternberg and W. M. Williams, Educational psychology (Allyn \& Bacon, Boston, MA, 2002).

[52] J. Nussbaum and J. D. Novak, An assessment of children's concepts of the Earth utilizing structured interviews, Sci. Educ. 60, 535 (1976).

[53] C. S. Wallace, E. E. Prather, and D. K. Duncan, A study of general education astronomy students' understandings of cosmology. Part IV. Common difficulties students experience with cosmology, Astron. Educ. Rev. 11, 010104 (2012).

[54] L. Hansson and A. Redfors, Lower secondary students' views in astrobiology, Res. Sci. Educ. 43, 1957 (2013).

[55] D. Lombardi, G. M. Sinatra, and E. M. Nussbaum, Plausibility reappraisals and shifts in middle school students' climate change conceptions, Learning Instr. 27, 50 (2013).

[56] U. Eriksson, C. Linder, J. Airey, and A. Redfors, Introducing the anatomy of disciplinary discernment: An example from astronomy, European J. Sci. Math. Educ. 2, 167 (2014). 